\title{
A System Dynamics approach to model photosynthesis at leaf level under fluctuating light
}

\author{
Nicole Salvatori ${ }^{1}$, Fabrizio Carteni ${ }^{2}$, Francesco Giannino $^{2}$, Giorgio Alberti ${ }^{3}$, Stefano \\ Mazzoleni $^{2}$, and Alessandro Peressotti ${ }^{3}$ \\ ${ }^{1}$ University of Trieste \\ ${ }^{2}$ Universita degli Studi di Napoli Federico II Dipartimento di Agraria \\ ${ }^{3}$ University of Udine
}

March 19, 2021

\begin{abstract}
It has been recognized the need to consider some photosynthetic processes in their transient states since those are more representative of the natural environment. The combination of mathematical models with the available data provides a tool to understand the dynamic responses of plants to fluctuating environments and can be used to make predictions on how photosynthesis would respond to unsteady state conditions. Here we present a leaf level system dynamic photosynthetic model based and validated on an experiment performed on two soybean varieties, the wildtype Eiko and the chlorophyll deficient mutant Minngold, grown in constant and fluctuating light conditions. This mutant is known to have similar steady-state photosynthesis compared to the green wildtype, but it is found to have less biomass at harvest. It has been hypothesized that this might be due to an unoptimized response to non-steady state conditions, therefore this mutant seems relevant to investigate dynamic photosynthesis. The model explained well the photosynthetic responses of these two varieties to fluctuating and constant light conditions and allowed to make relevant conclusions on the different dynamic responses of the two varieties. Furthermore, due to its simplicity, the model could provide the basis of an upscaled dynamic model at plant level.
\end{abstract}

\section{Hosted file}

Paper_draft.pdf available at https://authorea.com/users/402622/articles/514427-a-systemdynamics-approach-to-model-photosynthesis-at-leaf-level-under-fluctuating-light 


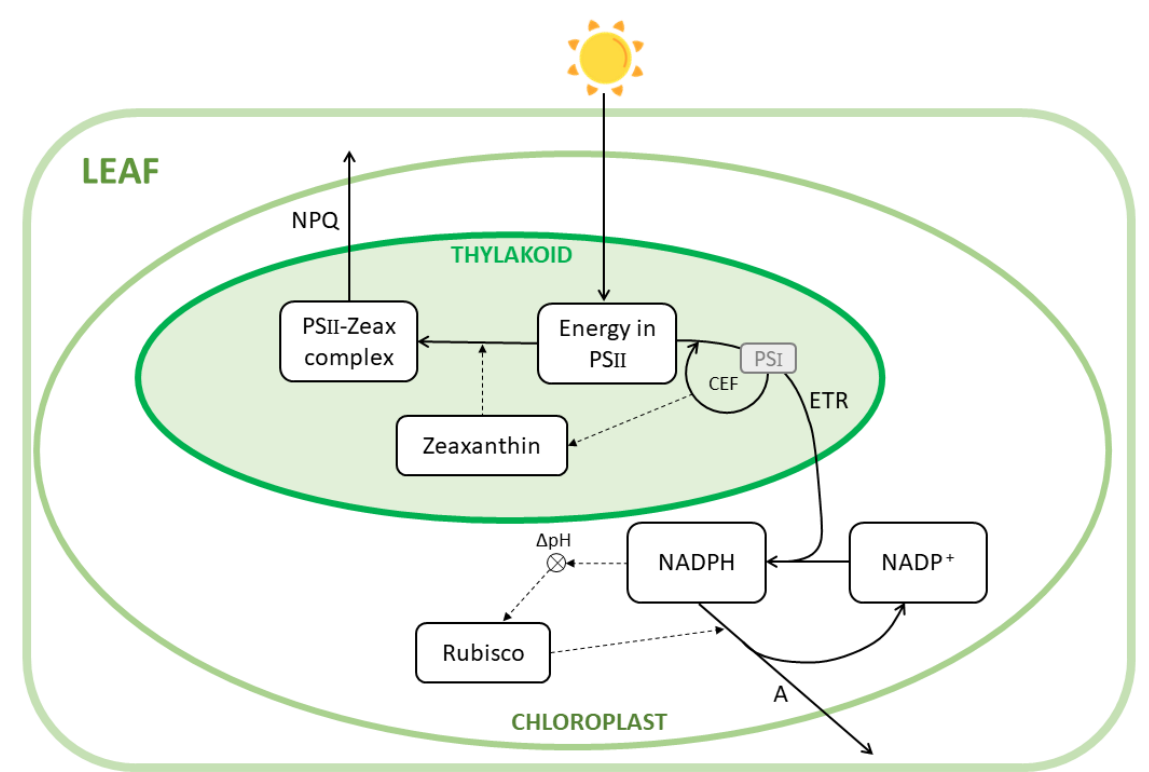

A

B
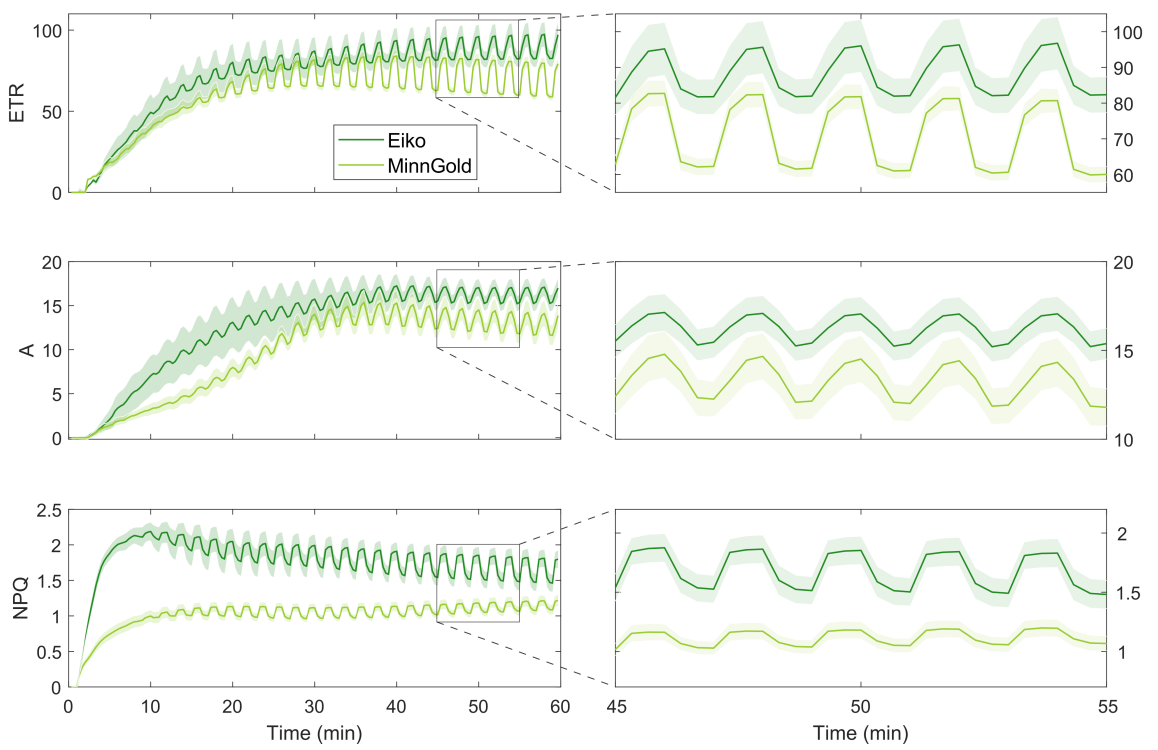

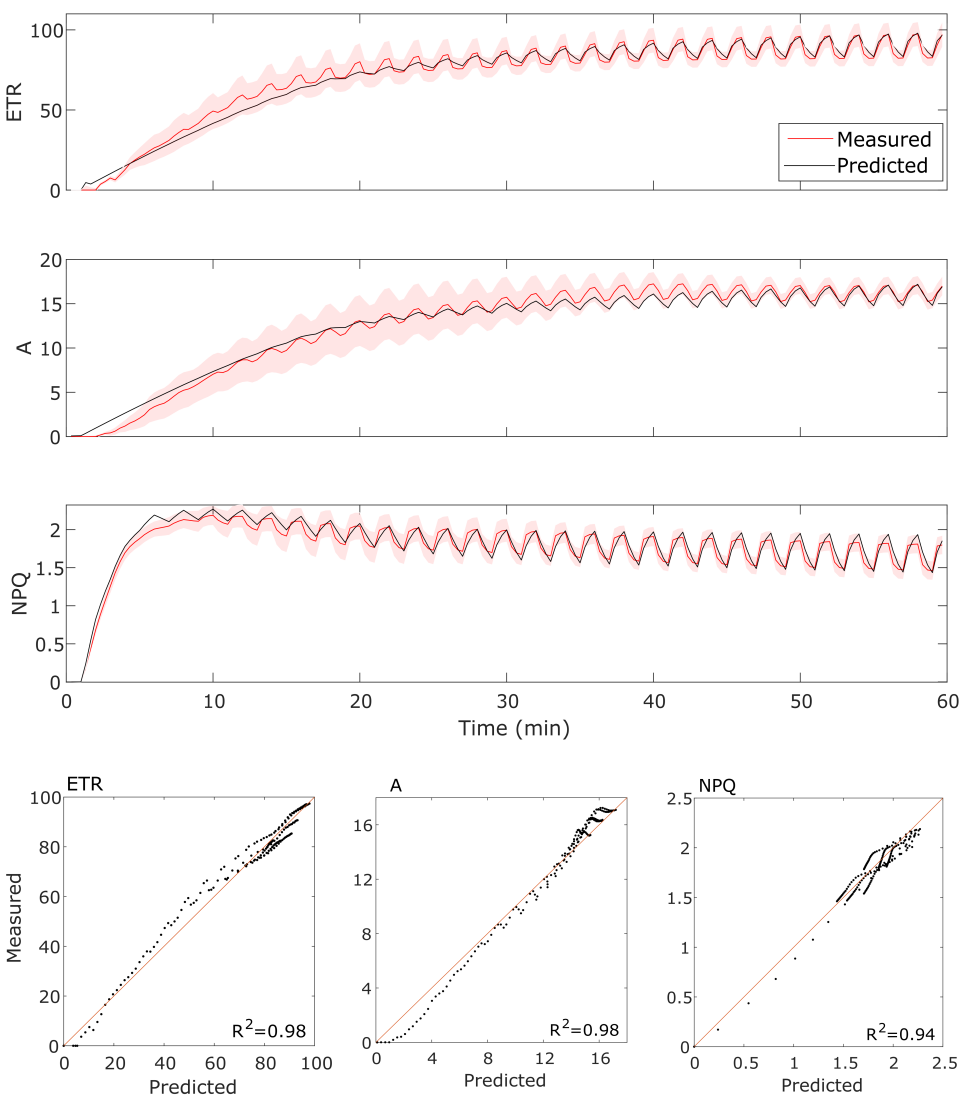

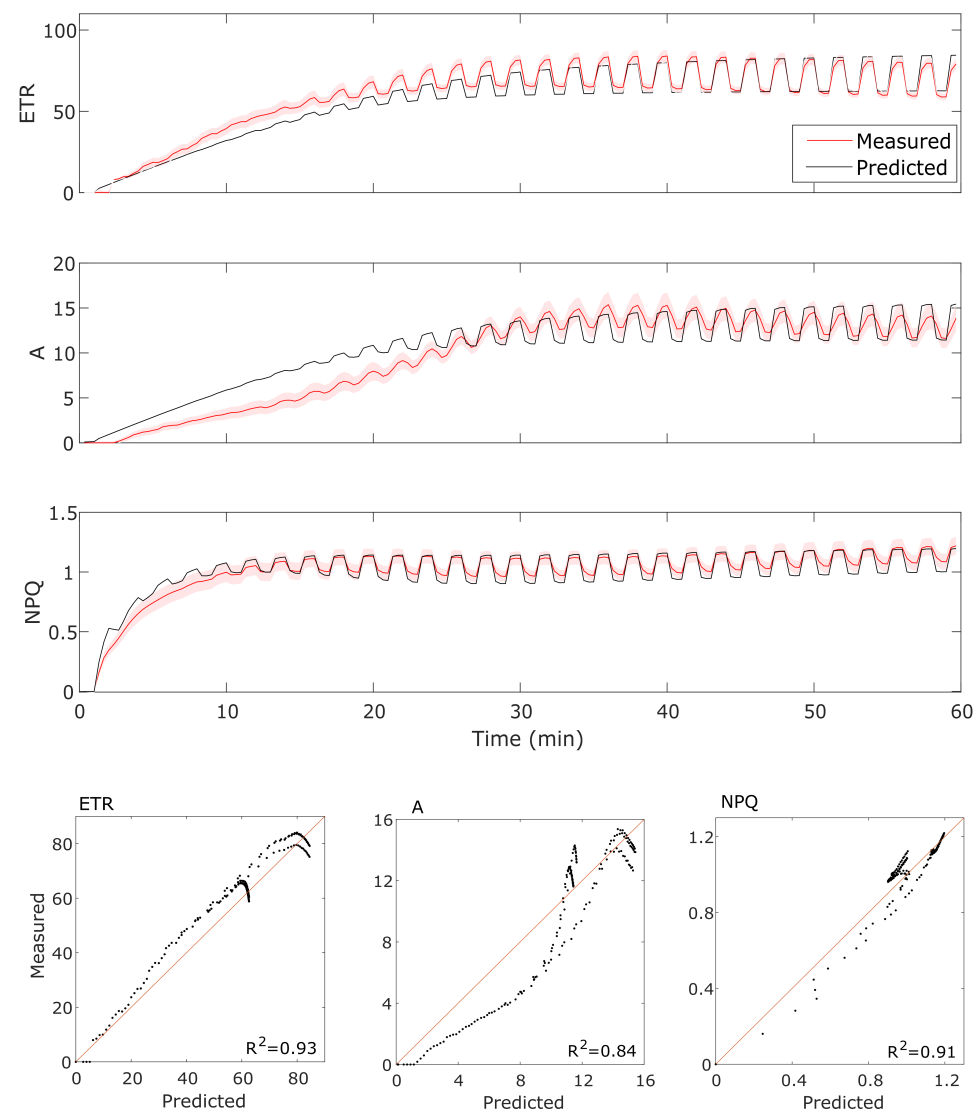

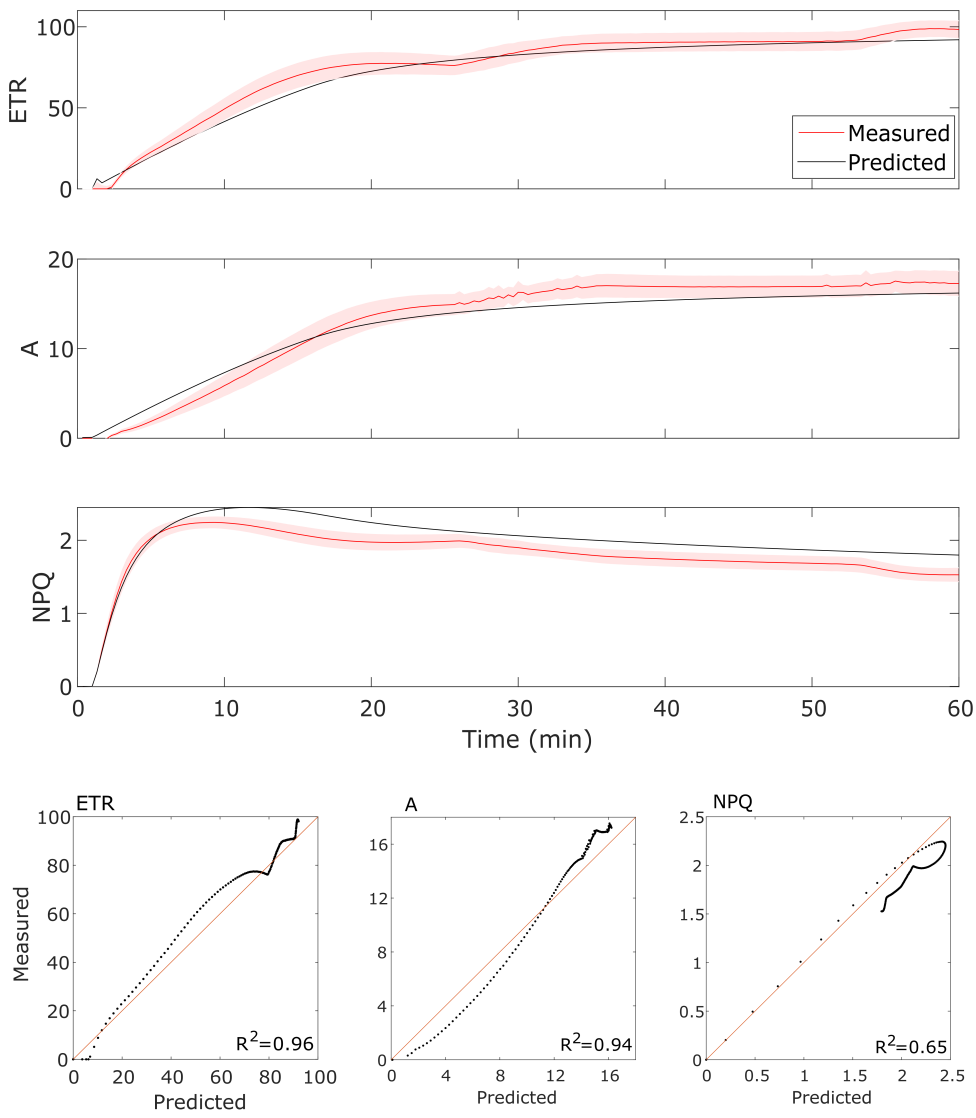

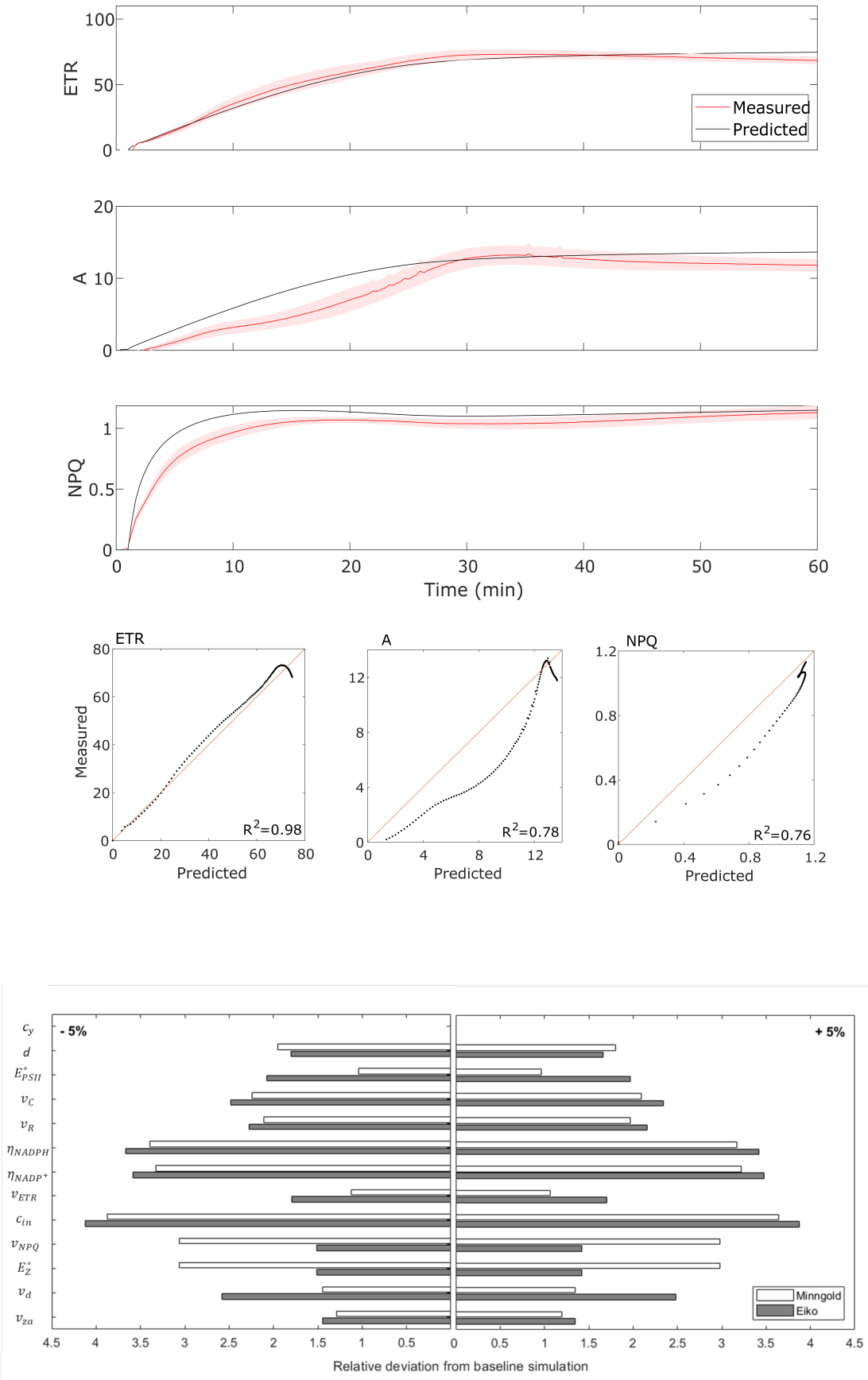
A

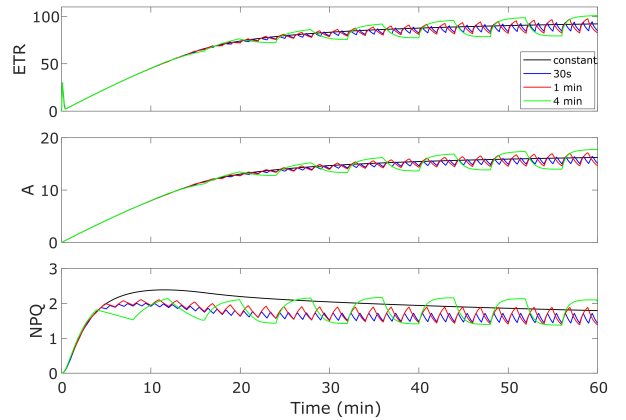

B

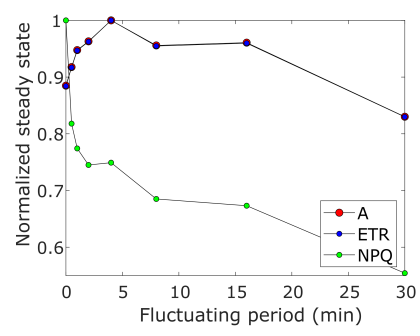

